\title{
Audience Costs and the Dynamics of War and Peace 0
}

\author{
Casey Crisman-Cox Texas A \& M University \\ Michael Gibilisco California Institute of Technology
}

\begin{abstract}
We estimate audience costs and examine their substantive effects on the evolution of interstate disputes by using an infinitely repeated and dynamic game of crisis escalation. Unlike past efforts, our approach estimates country-specific audience cost parameters without relying on proxy variables, such as democracy measures. Contrary to intuition, increases in a country's audience costs encourage it to initiate disputes in equilibrium because the costs serve as a commitment device during the subsequent crisis, incentivizing the country to stand firm and coercing its opponent to back down. Nonetheless, the results demonstrate that larger audience costs would result in more peace worldwide, as they also discourage potential opponents from initiating disputes. Beyond regime type, we find that a free press, provisions for executive appointment or removal, and historical rivalries are also important determinants of audience costs.
\end{abstract}

Replication Materials: The data, code, and any additional materials required to replicate all analyses in this article are available on the American Journal of Political Science Dataverse within the Harvard Dataverse Network, at https://doi.org/10.7910/DVN/XBNJD9.

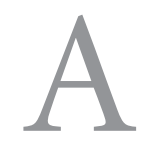

udience costs—or the costs leaders pay from backing down before their opponents in interstate disputes-are ubiquitous in international relations. Scholars use them to explain a variety of phenomena, including crisis bargaining, war duration, economic sanctions, and the democratic peace. This prominence has sparked two fervid debates: Do audience costs exist, and how would we know? Specifically, the former question asks to what extent are leaders punished for backing down (e.g., Snyder and Borghard 2011; Tomz 2007), whereas the latter concerns the appropriate methodology for answering such a question (e.g., Kurizaki and Whang 2015; Partell and Palmer 1999; Schultz 2001).

Two substantial impediments prevent progress in either debate. First, since Fearon's (1994a) canonical article, researchers traditionally proxy audience costs using democracy scales such as polity2, and these measures often determine case selection in qualitative studies and independent variables in quantitative ones (Partell and Palmer 1999; Snyder and Borghard 2011). Nonetheless, analyzing the quality and strength of different proxies has proven difficult (Levy 2012; Slantchev 2012). Scholars have yet to directly test the hypothesis that democratic or authoritarian institutions covary with audience costs because we lack a sufficient model for their measurement independent of regime-type proxies.

Second, the substantive effects of audience costs on conflict initiation are unclear due to two countervailing effects. On the one hand, a broad literature argues that increases in audience costs may discourage a given country from initiating disputes if the country expects its opponents to repeatedly stand firm in the future (Kurizaki and Whang 2015; Prins 2003; Weeks 2012). On the other hand, larger audience costs may also encourage their country to initiate a dispute if they simultaneously coerce opponents to more quickly back down in the subsequent interaction (Schultz 1999). Thus, when countries internalize the long-term strategies of their opponents, their unobservable strategies create a time dependence between current escalation decisions and the expected path of future conflict, confounding the relationship between audience cost

Casey Crisman-Cox is Assistant Professor, Department of Political Science, Texas A\&M University, 400 Bizzell Street, College Station, TX 77843 (c.crisman-cox@tamu.edu). Michael Gibilisco is Assistant Professor of Political Science, California Institute of Technology, 1200 East California Boulevard, Pasadena, CA 91125 (michael.gilbilisco@caltech.edu).

Thanks to Scott Abramson, Rob Carroll, Kevin Clarke, Allan Dafoe, Mark Fey, Tasos Kalandrakis, Brenton Kenkel, Bethany Lacina, Sergio Montero, Jack Paine, and Curt Signorino for helpful comments and suggestions. Earlier versions of the article also benefited from audiences at the 2015 SPSA meeting, the 2015 PolMeth conference, the 2015 EPSA meeting, the 2016 APSA meeting, and the University of Rochester.

American Journal of Political Science, Vol. 62, No. 3, July 2018, Pp. 566-580 
measures and dispute initiation. Such dynamic considerations also affect the propensity for countries to back down. For example, a country may be willing to back down and incur a relatively large audience cost in a dispute today only if it expects tomorrow's peace to be stable over the long run. In contrast, it would be less willing to incur those costs if the peace were merely transitory.

In this article, we address these issues head-on by structurally estimating a dynamic game-theoretic model of crisis escalation. As in Fearon (1994a), we model audience costs as a parameter capturing the (dis)utility a country receives when it backs down from a dispute before its opponent by using an explicit game form. The game is infinitely repeated, and countries fully anticipate the expected evolution of conflict and the possibility of incurring audience costs in equilibrium. We estimate audience costs using country-specific fixed effects, which do not depend on a priori determined variables, and we select the audience costs (along with other parameters and equilibria) that maximize the likelihood of the observed data. Specifically, we fit the model to Militarized Interstate Dispute Incident Profiles (MID-IP) data that record escalation decisions at the monthly level from 1993 to 2007 by using a new constrained maximum likelihood estimator developed by Su and Judd (2012) for dynamic models. Three major results emerge.

First, contrary to prevailing intuitions, we find that the second countervailing effect of audience costs dominates in the data. That is, increasing a given country's audience costs encourages it to initiate disputes along the path of play, an effect that emerges in $81 \%$ of directed dyads. In the estimated equilibria, audience costs serve as a commitment device: They tie the hands of their respective countries, thereby encouraging them to stand firm and coercing their opponents to back down in disputes. We find the hand-tying effect in 78\% of directed dyads, where increasing a country's audience costs forces it to stand firm more frequently. Likewise, the coercion effect appears in $75 \%$ of directed dyads, where increasing a country's costs compels its opponent to concede more often. Although the hand-tying and coercion effects are well studied in the literature, the finding that enhanced audience costs incentivize countries to initiate conflicts runs counter to previous findings in reduced-form analyses (Clark and Nordstrom 2005; Prins 2003; Weeks 2012). While audience costs and conflict initiation are negatively associated in some of our estimated equilibria, this trend appears in only a small minority of directed dyads.

Second, we use the model to address a substantive puzzle: Do higher audience costs lead to more or less conflict worldwide? On the one hand, increasing a country's audience costs incentivizes it to stand firm and initiate disputes. On the other hand, audience costs also coerce opponents to back down. The peace-enhancing effects dominate in the data; in two-thirds of directed dyads, larger costs reduce the long-run probability that the dyad enters a dispute. In $80 \%$ of undirected dyads, an identical increase in both countries' audience costs results in a higher propensity for peace in the long run. One reason for these results is that audience costs have a deterrent effect on dispute initiation. Countries avoid beginning conflicts with opponents with enhanced audience costs and the credibility that the costs entail.

Finally, we test the hypothesis that standard proxies for audience costs correlate with our estimates and find that they are fair, but underwhelming, first approximations. Although democracy and authoritarian regime types are important predictors, other systemic and domestic factors influence audience costs. For example, the existence of an interstate rival attenuates the penalties leaders face for backing down in a dispute. Democracies with rivals have, on average, audience costs that are roughly similar to autocratic regimes with legal provisions for executive removal (e.g., China), suggesting that democratic voters may provide leaders with some leeway when they escalate disputes with rivals. Additionally, a free press can strongly increase audience costs, confirming results derived from the formal model in Slantchev (2006).

Finally, while the analysis primarily contributes to debates concerning audience costs, our rich framework produces additional implications for the wider international relations literature. We find that trading partners and joint democracies are less inclined to enter wars, whereas no such aversion to crises exists. Thus, a liberal peace may prevent more hostile conflicts, but not lower-level disputes. In addition, our results provide mixed support for the two systemic theories of conflict in Braumoeller (2008). In peace, the expectation of conflict deters escalation, but in crisis and war, it encourages or spirals further escalation. Such nuances offer one explanation as to why conflicts cluster temporally and peace is self-enforcing.

\section{Modeling Audience Costs and Disputes}

We follow the lead of Fearon (1994a, 582) and define audience costs as the (dis) utility a country receives from backing down in an international dispute before its opponent. In a similar vein, Slantchev $(2012,377)$ defines the first core premise of audience cost theory as "backing down in a crisis makes [a country] suffer costs in addition to those arising from conceding the contests." As discussed below, 
this definition is tractable and permits identification from standard event data on interstate disputes.

Although our conceptualization of audience costs holds a prominent place in the literature, it sidesteps two theoretical explorations that have developed since Fearon's seminal work. In one development, scholars often interpret audience costs as the punishment leaders receive from initiating a threat but failing to follow through on it. ${ }^{1}$ In this setup, audience costs only affect countries' payoffs when they initiate disputes (Kurizaki and Whang 2015; Schultz 1998, 1999). Several exceptions exist, however, as other theories require both initiators and targets to receive costs for backing down (Fearon 1994b; Kurizaki 2007; Schultz 2001). This latter approach is appropriate when "crisis diplomacy takes place before domestic audiences on both sides" (Kurizaki 2007, 545).

In the second development, researchers have considered endogenous audience costs, allowing them to grow over the dispute's duration or be products of strategic choices (Fearon 1994a; Leventoglu and Tarar 2005). Yet previous empirical work, including both reduced-form and structural approaches, treats audience costs as fixed and not being subject to strategic choices. In this article, we adopt the simplified conceptualization, where audience costs are country specific and do not depend on the historical evolution of disputes. This helps simplify already complicated estimation and counterfactual exercises, thereby serving as a useful starting point to a problem in which theory has traditionally outpaced empirics.

In addition, our framework treats countries as longlived actors, deciding whether to engage in conflict given their opponent's expected actions not only today but also tomorrow. Long-standing theories, historical accounts, and common intuitions maintain that countries and national leaders are strategic and forward-looking. Thus, long-term expectations influence whether countries incur audience costs. In a crisis, a country may be more likely to back down and incur an audience cost today if it expects a stable peace to emerge subsequently. In this case, a country trades an immediate (audience) cost for a delayed benefit (peace). Conversely, it would be less likely to back down when the benefits of peace are more fleeting.

Finally, we remain agnostic about the particular mechanisms generating audience costs, but we investigate their determinants in a postestimation exercise. This approach has several advantages. Most prominently, we avoid introducing an avenue of omitted variable bias into

${ }^{1}$ In experiments, audience costs refer to the disapproval leaders create when they say one thing but do another (Tomz 2007). the analysis, which is likely to arise because audience costs originate from several highly correlated factors including democratic institutions, voter repressiveness, leader removal, national honor, among others (Chiozza and Goemans 2011; Dafoe and Caughey 2016; Levy 2012; Smith 1998). ${ }^{2}$ Instead, we treat audience costs as a country-specific parameter to be estimated. In a similar vein, this fixed-effects approach reduces the potential for separation that may arise from modeling audience costs as functions of highly collinear variables.

Because we adopt a structural approach, our endeavor is most similar to Kurizaki and Whang (2015), and we build upon their work in four ways. First, they use polity 2 to proxy audience costs by assuming the costs are a linear function of democracy; we impose no such assumption. Second, the two theoretical models differ considerably. Kurizaki and Whang (2015) use a version of the one-shot crisis-signaling model with sequential moves from Lewis and Schultz (2003), in which initiators only incur audience costs once. In this paper, we construct a dynamic model with simultaneous choices, where countries are infinitely lived, accommodating the long-term costs and benefits of backing-down and standing firm. Third, a drawback from using the crisis-signaling model to study interstate conflict is that the analysis almost certainly requires a very specific data set from Schultz, Lewis, and Zucco (2012), which covers the interwar period (191939). In contrast, the dynamic model is more flexible with its informational requirements, and we use the standard MID-IP data set, covering a more contemporary period (1993-2007). Finally, although the two models are quite different, both may admit multiple equilibria under certain payoffs. Standard estimation techniques (e.g., Signorino 1999) do not account for this multiplicity, leading to inconsistent estimates and incorrect counterfactuals (Jo 2011). Our estimation strategy and counterfactual exercises, however, avoid these issues.

\section{Structural Model}

In this section, we construct a dynamic game of crisis escalation. Because estimation is our goal, we include action-specific shocks that are private information and allow payoffs to depend on observed covariates. Consider two countries. We use $i$ to denote an arbitrary country and $j \neq i$ its opponent.

\footnotetext{
${ }^{2}$ As a result, we cannot compare our audience cost estimates to their substantive effects on leader approval identified in the experimental literature (Levy et al. 2015; Tomz 2007).
} 
Consider two countries. We use $i$ to denote an arbitrary country and $j \neq i$ its opponent. Time is discrete and indexed by $t=1,2, \ldots$. In each period $t$, country $i$ first observes a common state variable $s^{t} \in\{1,2,3\}$ and a private state variable $\varepsilon_{i}^{t}$, which represents private information, unknown to opponent $j$, that country $i$ has about the costs/benefits of taking particular actions in period $t$. The variable $s^{t}$ represents the current level of hostility, where $s^{t}=1$ denotes that the countries are in a state of peace, $s^{t}=2$ a state of crisis, and $s^{t}=3$ a state of war. ${ }^{3}$ Each country then simultaneously chooses a level of hostility against its competitor. Let $a_{i}^{t} \in\{1,2,3\}$ denote country $i$ 's action in period $t$, and a profile of actions is $a^{t}=\left(a_{i}^{t}, a_{j}^{t}\right)$. Here, $a_{i}^{t}$ takes the values 1,2 , and 3 , which indicate peaceful, crisis-level (threat/demand), and warlevel (attack/invasion) actions, respectively.

The common state variable $s^{t}$ evolves according to past actions, and we assume escalation is deterministic and unilateral, that is, $s^{t}=\max \left\{a_{i}^{t-1}, a_{j}^{t-1}\right\} .{ }^{4}$ Thus, the model captures situations in which a country declares war $\left(a_{i}^{t}=3\right)$ on its opponent, and the next period begins with the two countries in a state of war $\left(s_{i}^{t+1}=3\right)$. We denote country's $i$ 's private information about the cost of action $a_{i}$ in period $t$ as $\varepsilon_{i}^{t}\left(a_{i}^{t}\right) \in \mathbb{R}$. The private information, $\varepsilon_{i}^{t}\left(a_{i}^{t}\right)$, is an independently and identically distributed Type 1 extreme value across actions, players, and states, which are standard distribution and independence assumptions in these types of games.

Let $\theta$ denote a vector of relevant structural parameters to be estimated. Country $i$ 's per-period payoff against country $j$ is given as $u_{i j}\left(a^{t}, s^{t} ; \theta\right)+\varepsilon_{i}^{t}\left(a_{i}^{t}\right)$, where $u_{i j}$ is $i$ 's deterministic utility and $\varepsilon_{i}$ is $i$ 's (stochastic) private information. Given a sequence of action profiles, states, and action-specific shocks $\left\{\left(a^{t}, s^{t}, \varepsilon_{i}^{t}\right)\right\}_{t=1}^{\infty}$, country $i$ 's total payoff is the discounted sum of per-period utilities:

$$
\sum_{t=1}^{\infty} \delta^{t-1}\left[u_{i j}\left(a^{t}, s^{t} ; \theta\right)+\varepsilon_{i}^{t}\left(a_{i}^{t}\right)\right],
$$

where $\delta \in[0,1)$ denotes a common discount factor. ${ }^{5}$

\footnotetext{
${ }^{3}$ Hereafter, a state denotes the commonly observed level of hostility $s^{t}$, and we refer to the game's actors as countries. We use the terms dispute and conflict interchangeably to refer to periods in which the path of play resides in states 2 and 3.

${ }^{4}$ Unilateral escalation is common in the crisis and conflict literature (Fearon 1994a; Kurizaki and Whang 2015; Schultz 2001).

${ }^{5}$ Notice we do not include $\delta$ in the parameters to be estimated. Without additional structure, it is difficult to identify $\delta$ in these types of models, and previous articles have traditionally assumed a fixed discount factor throughout (Arcidiacono et al. 2016; Pakes, Ostrovsky, and Berry 2007). Here, we fix $\delta=0.9$.
}

We endow $u_{i j}$ with the following functional form:

$$
\begin{aligned}
u_{i j}(a, s ; \theta)= & \underbrace{x_{i j} \cdot \beta(s)}_{\begin{array}{c}
\text { state-specific } \\
\text { payoff }
\end{array}}+\underbrace{z_{i} \cdot \kappa\left(a_{i}\right)}_{\begin{array}{c}
\text { action-specific } \\
\text { payoff }
\end{array}}+\underbrace{\alpha_{i} \mathbb{I}\left[a_{j} \geq s>a_{i}\right]}_{\begin{array}{c}
\text { country-specific } \\
\text { audience cost }
\end{array}} \\
& +\underbrace{\gamma(s) \mathbb{I}\left[a_{i}>1\right] \mathbb{I}\left[a_{j}>1\right]}_{\begin{array}{c}
\text { spiral/deterrence } \\
\text { effect }
\end{array}} .
\end{aligned}
$$

Country $i$ 's utility consists of four components. First, it receives a state-specific payoff, $x_{i j} \cdot \beta(s)$, from being in state $s$ with country $j$, where $x_{i j}$ is a vector of dyadspecific variables and $\beta(s)$ is a vector of associated coefficients. Dyadic variables could be directed (e.g., military capability ratios) or undirected (e.g., minimum democracy). ${ }^{6}$

Second, regardless of the state, if country $i$ chooses action $a_{i}, i$ pays some costs $z_{i} \cdot \kappa\left(a_{i}\right)$, where $z_{i}$ is a vector of country-specific variables and $\kappa\left(a_{i}\right)$ is a vector of associated coefficients. ${ }^{7}$ These costs of escalation capture important transaction costs from declaring war, formally threatening a opponent, or maneuvering military troops to a border area. ${ }^{8}$ Notice that $i$ 's cost of action $a_{i}$ does not depend on characteristics of $j$. This independence is an important identification assumption, but paired with the state-specific payoff, this leads to a natural interpretation: Although the United States pays the same cost from declaring war on Afghanistan and on Russia, it can still possess a preference for being at war with Afghanistan over being at war with Russia. We adopt the normalization that $\beta(1)=\kappa(1)=0$; that is, the payoffs $x_{i j} \cdot \beta(s)$ and $z_{i} \cdot \kappa\left(a_{i}\right)$ are relative to the baseline payoffs for the peaceful state and action, respectively.

The last two components in a country's utility function depend on the actions of its opponent. The parameter $\alpha_{i}$ is a country-specific value and measures $i$ 's audience costs. That is, if $i$ and $j$ are engaged in a dispute $(s>1), j$ continues or escalates the current level of conflict $\left(a_{j} \geq s\right)$

${ }^{6}$ The payoff $x_{i j} \cdot \beta(s)$ may represent country $i$ 's expected utility from some lottery as the outcome does not affect payoffs or transitions. In the war lottery where $p_{i j}$ represents a probability of victory, $\pi_{i j}$ the benefit of winning, and $c_{i j}$ the cost of war, the war-state payoff takes the form $x_{i j} \cdot \beta(3)=p_{i j} \pi_{i j}-c_{i j}$.

${ }^{7}$ Although we operationalize the costs of the crisis- and war-level actions in a similar manner, the model incorporates the possibility that these actions entail more substantive differences. The two actions transition the game to strategically different states, and they generally produce diverging propensities for incurring audience costs. This setup is rich enough to uncover empirical differences once the model is taken to data.

${ }^{8}$ This may appear to be a nonstandard modeling choice because these costs of escalation are not considered in previous models, but this version subsumes the case in which the coefficients $\kappa\left(a_{i}\right)$ are zero. 
and $i$ backs down $\left(a_{i}<s\right)$; then $i$ incurs cost $\alpha_{i}$. Intuitively, this means that countries never acquire audience costs when in peace or if their opponents do not escalate/maintain the current conflict. Essentially, countries receive audience costs when they de-escalate the dispute before their rival, although size of the audience costs is fixed throughout the dispute. ${ }^{9}$ The $\gamma(s)$ parameters are state-specific values measuring how $i$ 's cost of escalation varies with $j$ 's actions in state $s$. When $\gamma(s)>0$, $i$ 's cost of escalation $\left(a_{i}>1\right)$ decreases when $j$ escalates in state $s$. Similarly, when $\gamma(s)<0$, i's cost of escalation increases when $j$ escalates. Thus, $\gamma(s)$ represents other strategic incentives as to why a country does not escalate a conflict independently of audience costs, including potential second-strike (dis)advantages. For example, if $i$ receives a large benefit in state $s$ when its opponents attack first (e.g., support from an international community), then $\gamma(s)$ would be negative.

We characterize Bayesian-Nash equilibria in stationary Markovian strategies (equilibria, hereafter) as is standard in these games. Consider $i$ 's net-of-shock expected utility from choosing action $a_{i}$ in state $s$, denoted $v_{i}\left(a_{i}, s\right)$, and let $v_{i}$ denote the vector of expected utilities for country $i$. Because $\varepsilon_{i}$ is a distributed Type 1 extreme value, $i$ chooses $a_{i}$ in state $s$ with probability

$$
P\left(a_{i}, s ; v_{i}\right)=\frac{\exp \left(v_{i}\left(a_{i}, s\right)\right)}{\sum_{a_{i}^{\prime}} \exp \left(v_{i}\left(a_{i}^{\prime}, s\right)\right)},
$$

that is, equilibrium choice probabilities take the standard multinomial logit form. As in Signorino (1999), the expected utilities, $v_{i}$, are endogenous to equilibrium play. Unlike most previous work, a closed-form solution for these values does not exist due to the game's infinite horizon and simultaneous moves. In Appendix A in the supporting information (SI), we demonstrate that profile $v=\left(v_{i}, v_{j}\right)$ is an equilibrium if and only if it satisfies a system of 18 smooth equations, $\Phi(v ; \theta)=v$.

In Appendix B in the SI, we analyze an equilibrium for specific parameter settings to better illustrate the model's dynamics. A novel comparative static emerges: increasing a country's audience cost increases the probability that the given country initiates a dispute along the path of play. Schultz (1999) finds a similar result with a one-shot signaling game, but our result does not require signaling

\footnotetext{
${ }^{9}$ We could alter the model so that only initiators incur audience costs by expanding the state space, where there are four dispute states including crisis initiated by $i$ and war initiated by $i$. Such an extension involves estimating an additional 2,148 parameters describing equilibrium play. Instead, we allow both countries to incur audience costs in disputes, as in Fearon (1994a), Kurizaki (2007), and Schultz (2001).
}

incentives and arises in a setting where both countries may incur audience costs. In the subsequent sections, we the fit the model to data and examine whether this relationship holds given our estimated equilibria.

\section{Empirical Strategy Constrained Maximum Likelihood}

We estimate the model using a full information constrained maximum likelihood estimator (CMLE), as advocated by Su and Judd (2012). Given our application, this estimator has significant advantages over other methods (Aguirregabiria and Mira 2007; Hotz and Miller 1993; Rust 1987). The procedure does not repeatedly compute equilibria, a process that is further complicated by the possibility of multiple equilibria. In addition, it does not require consistent first-stages estimates of equilibrium choice probabilities, which is particularly important for the rare-event nature of interstate disputes. Finally, the CMLE avoids convergence issues that arise when iterating two-step approaches (Egesdal, Lai, and Su 2013)..$^{10}$

We consider $D$ dyads or games as described above. We index dyads by $k \in\{1, \ldots, D\}$ and include the superscript $k$ hereafter. We use data that can be summarized as a list $\{X, Z, Y\}$. Here, $X$ and $Z$ are matrices of ordered-dyad and country-specific variables, respectively, which enter the stage utilities through Equation (1). In addition, $Y$ is a collection of matrices detailing observed state and action profiles for each dyad, that is, $Y^{k}=\left(s^{k t}, a_{i^{k}}^{k t}, a_{j^{k}}^{k t}\right)_{t=1}^{T}$, and $T$ is the total number of observed time periods. Let $\bar{\theta}$ denote the true vector of parameters. For each dyad $k$, we assume the data $Y^{k}$ were generated from a single equilibrium, $\bar{v}^{k}$, that is, $\Phi^{k}\left(\bar{v}^{k} ; \bar{\theta}\right)=\bar{v}^{k}$. While multiple equilibria potentially exist in the game between the countries $i^{k}$ and $j^{k}$, the procedure requires that $Y^{k}$ comes from only one of these. Let $\mathbf{v}=\left(v^{1}, \ldots, v^{D}\right)$ denote the vector of all profiles of expected utilities. The log-likelihood takes the following form:

$$
\begin{aligned}
\mathcal{L}(\mathbf{v} \mid Y)= & \sum_{k=1}^{D} \sum_{t=1}^{T}\left[\log P\left(a_{i^{k}}^{k t}, s^{k t} ; v_{i^{k}}^{k}\right)\right. \\
& \left.+\log P\left(a_{j^{k}}^{k t}, s^{k t} ; v_{j^{k}}^{k}\right)\right],
\end{aligned}
$$

\footnotetext{
${ }^{10}$ One drawback of the CMLE is that the procedure requires solving a constrained optimization problem, which may be difficult to implement using standard statistical software. Su and Judd (2012) describe how researchers can use open-sourced, industrial software instead. Appendix C in the SI describes our implementation.
} 
which is a standard multinomial log-likelihood summed over dyads, time periods, and players. With a slight abuse of notation, the CMLEs, $(\hat{\mathbf{v}} ; \hat{\theta})$, solve the following constrained optimization problem:

$$
\max _{(\mathbf{v} ; \theta)} \frac{1}{T} \mathcal{L}(\mathbf{v} \mid Y)
$$

subject to $\Phi^{k}\left(v^{k} ; \theta \mid X, Z\right)=v^{k}, \quad k=1, \ldots, D$. (4)

Standard results on Lagrange multiplier tests, found in Silvey (1959), guarantee that the CMLE is consistent in $T$ and characterize the estimator's asymptotic distribution. Consistency in the number of games or dyads is not guaranteed, as there is an obvious incidental parameters problem, where an additional dyad requires estimating 18 new equilibrium constraint parameters. We still gain leverage by pooling information across dyads when $T$ is sufficiently large, however. We relegate further estimation details to Appendix C in the SI, and Appendix D contains a Monte Carlo illustrating the properties of the CMLE on data sets of similar size to the one we construct in this article.

\section{Data}

We use the MIDs incident-level data known as MID-IP 4.01 (Kenwick et al. 2013) to define each dyad's observed path of play, $Y^{k}$. The data record actions taken by the individual countries within interstate disputes between 1993 and 2010. These actions are then used to create the state transitions. Dispute numbers determine which country or countries the actions were taken against. In our framework, a time period is a calender month because approximately $50 \%$ of incident reports include no more precise timing information. The actions recorded by the MID-IP are on the standard 22-point MID scale, ranging from no action to joining an interstate war. We use this scale to form the three levels of hostility countries can take against each other: war, crisis, and peace. We code a "warlevel" action if country $i$ attacks or takes a more hostile action against country $j$ in period $t$ (MID-IP actions 16-21). A "crisis-level" action is recorded if the country commits an action that is between a threat and an attack (MID-IP actions 1-15).

We follow Whang, McLean, and Kuberski (2013) and construct the data set in two steps. First, to avoid selection bias, we fill in peaceful actions for all country-dyadmonths in which the MID-IP database does not include a military incident (Huth and Allee 2002). Second, we define a set of "politically relevant dyads" that restricts the sample to every dyad that has entered the MID-IP data. Ultimately, the data contain 179 dyads with 180 time

\section{TABLE 1 Distribution of Transitions in the Data}

\begin{tabular}{lcc}
\hline Transition & Percent of Data & $\begin{array}{c}\text { Percent within } \\
\text { Each State }\end{array}$ \\
\hline Peace $\rightarrow$ Peace & 92.5 & 97.0 \\
Peace $\rightarrow$ Crisis & 1.82 & 1.91 \\
Peace $\rightarrow$ War & 1.09 & 1.14 \\
Crisis $\rightarrow$ Peace & 1.81 & 71.8 \\
Crisis $\rightarrow$ Crisis & 0.49 & 19.6 \\
Crisis $\rightarrow$ War & 0.22 & 8.62 \\
War $\rightarrow$ Peace & 1.09 & 53.6 \\
War $\rightarrow$ Crisis & 0.21 & 10.2 \\
War $\rightarrow$ War & 0.74 & 36.2 \\
\hline
\end{tabular}

Note: The middle column displays the probability distribution over the possible transitions, and the rightmost column presents the conditional distribution in each state.

periods each; approximately $95.4 \%$ of observed states are peace, and $97 \%$ of actions are peace-level actions. Table 1 records the nine different types of possible transitions and provides preliminary evidence that countries condition their behavior on the state variable of interest. That is, the conditional distribution of transitions changes substantially across the observed states.

The model gains leverage on estimating audience costs through two observable moments: the probability with which a country (a) initiates disputes in peace and (b) backs down within a dispute. To see this, hypothetically fix the strategies of the two actors in all periods such that they place positive probability on every action in every state. Then increasing i's audience costs (i.e., $\alpha_{i}$ moves to $-\infty$ ) has two important effects. First, $i$ 's expected utility of initiating conflict $\left(a_{i}>1\right)$ once in peace $(s=1)$ decreases because initiation certainly transitions the game into a state in which $i$ receives an audience cost with a fixed probability. Second, i's expected utility of playing the peace action $\left(a_{i}=1\right)$ in a dispute $(s>1)$ will change as well, but the direction of this change will depend on $j$ 's strategy. If $j$ stands firm with a sufficiently large probability, then $i$ 's utility of playing peace will decrease as it expects to subsequently incur audience costs. In contrast, if $j$ is likely to play the peaceful action, then $i$ 's utility of playing peace may increase, as $i$ would prefer to de-escalate the dispute, transitioning to a peaceful state without audience costs.

These dynamics have two important implications. First, we cannot identify a country's audience cost parameter if it has never been in a dispute with another country in the data, although we do not require that it initiate or back down in a dispute. Including such a country (e.g., Costa Rica) would lead to separation because 
its contribution to the likelihood function will be strictly increasing as its audience cost parameters become more negative. ${ }^{11}$ Second and more importantly, the above discussion highlights the importance of equilibrium analysis. Essentially, the discussion fixes the strategies of both players, thereby ignoring the indirect effects of audience costs that will change $j$ 's equilibrium strategy and therefore $i$ 's expected utility calculations as well. As we demonstrate below, the estimated equilibria can and oftentimes produce comparative statics that diverge from the naive predictions in the previous paragraph.

To isolate the effects of audience costs, we also control for other reasons why countries initiate a dispute or back down. First, we control for the possibility of second-strike (dis)advantages or a general preference for peaceful actions and states. The former are controlled for by the parameters $\gamma(s)$, whereas the latter are captured by including constants in $x_{i j}$ and $z_{i}$. In addition, we include other control variables common to the interstate conflict literature. At the dyadic level, we use the minimum democracy level in the dyad, the logged capability ratio, and the square root of the trade interdependence. We measure the minimum level of democracy using the standard Polity IV database. Capability ratios are computed as the ratio of CINC scores from the Correlates of War (COW) National Material Capabilities 3.0 (NMC) dataset (Singer, Bremer, and Stuckey 1972). Trade interdependence is measured in the usual fashion (Gartzke 1998; Oneal and Russett 1997), where country $i$ 's interdependence on country $j$ is the sum of exports and imports between $i$ and $j$ divided by $i$ 's gross domestic product (GDP). Trade data come from the COW dyadic trade data (Barbieri, Keshk, and Pollins 2009), supplemented by data from Gleditsch (2002). GDP data are from the Penn World Table (PWT) 8.0 (Feenstra, Inklaar, and Timmer n.d.) and supplemented with data from the World Bank and the United Nations. For the variables associated with country-specific costs, we include logged GDP per capita (from PWT) and logged military personnel per capita (from NMC).

We take the mean values over the course of the time period in the study (1993-2007) to produce values in $x_{i j}$ and $z_{i}$. While there is a legitimate concern that some of these measures are endogenous to the conflict process itself, the variables in the analysis show little change over the time frame considered here. Even when these variables do change, there is no correlation between these changes

\footnotetext{
${ }^{11}$ In a similar vein, countries that only enter one dyad and one crisis within that dyad (e.g., Ghana with South Africa) tend to have larger standard errors associated with their audience costs.
}

and the observed states and actions. See Appendix E in the SI for more details.

\section{Audience Costs}

Figure 1 presents the estimated country-specific audience costs and their $95 \%$ confidence intervals, sorted by magnitude. ${ }^{12}$ Even though the parameters $\alpha_{i}$ can take on any value in estimation, all estimates are negative, suggesting that leaders are punished for backing down. The countries with the 10 largest (most negative) audience costs are mostly democracies, but notable exceptions exist to the idea that democracy and audience costs are synonymous. Many autocracies and anocracies exhibit substantial audience costs (e.g., Turkmenistan and Belarus). This offers some prima facie evidence in favor of arguments suggesting that autocrats in weak states with real removal threats face large audience costs. Despite this, preliminary difference-in-means tests indicate that democracies have larger audience costs than both autocracies and anocracies $(\mathrm{p}<.05)$, but a test finds no difference between the latter two groups.

Although democracies have larger audience costs than autocracies on average, several exceptions to this trend are involved in historically salient and persistent conflicts. For example, North and South Korea have similar audience costs, as South Korea's audience costs are very moderate (less negative) compared to other advanced democracies. One reason for this is that South Korea exists in a state of perpetual siege, suggesting that voters are more willing to give their leader free range to do whatever she thinks is best to avoid a costly war. ${ }^{13}$ A similar story explains why Israel and India both have moderate-for democracies-audience costs.

Finally, comparing across autocratic institutions, the audience cost parameters vary in expected ways. We analyze the degree to which our estimated audience costs match the theoretical predictions regarding autocratic regime types in Weeks $(2008,2012) .{ }^{14}$ In the case of

${ }^{12}$ Point estimates in table format can be found in Appendix F in the SI.

${ }^{13}$ Other explanations for South Korea's moderate audience costs include its dependence on U.S. military support and lack of wartime operational control. The trend of smaller audience costs among democracies with rivals holds more generally, however. Audience costs and the number of rivals, as defined in Thompson and Dreyer (2012), have a correlation coefficient of 0.34 among democracies, which is significant at the $\mathrm{p}<.01$ level.

\footnotetext{
${ }^{14}$ Although only the former deals explicitly with audience costs, both generate predictions about the political costs leaders face from domestic audiences.
} 
Figure 1 Country-Specific Audience Costs, Labeled with Three-Letter COW Codes

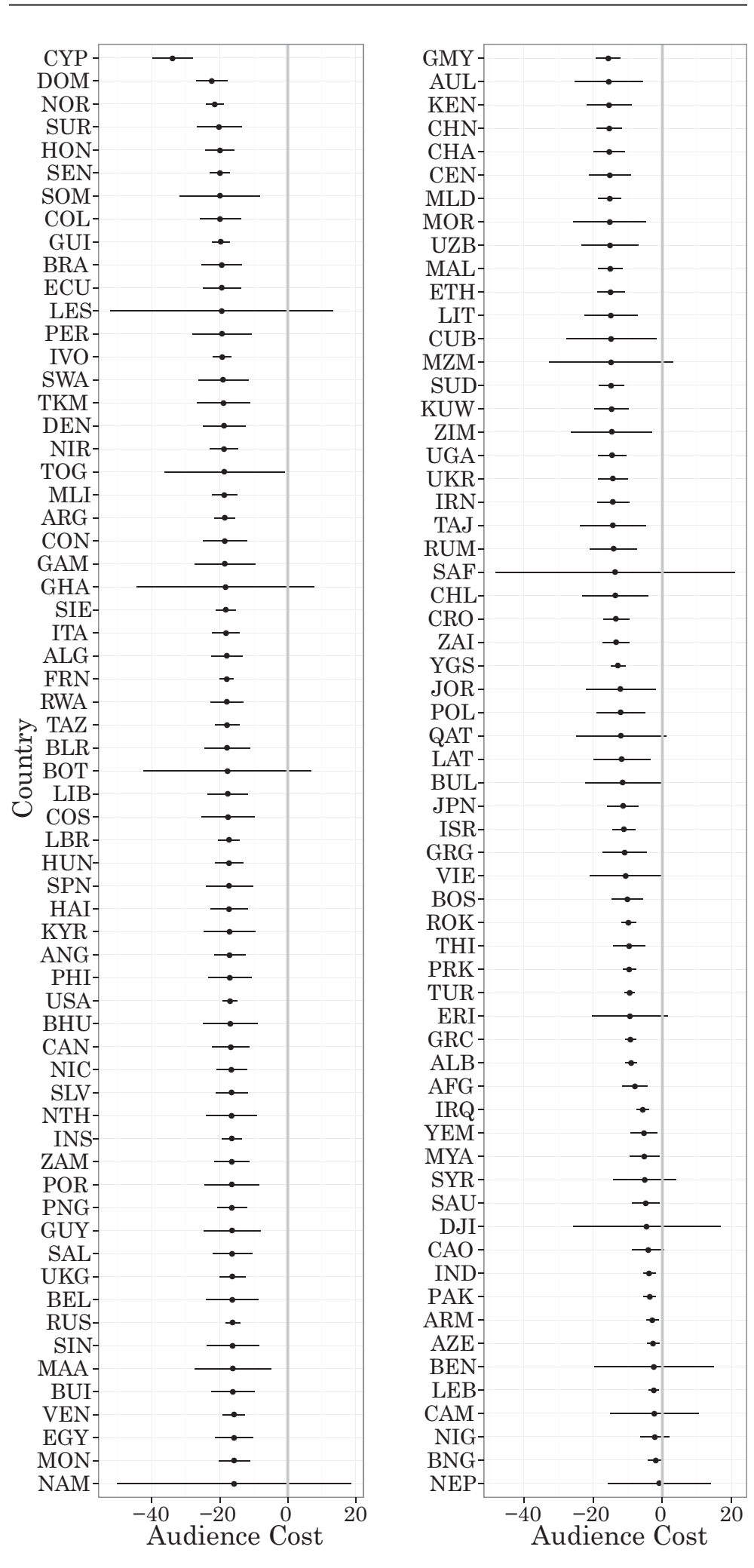




\section{TABLE 2 Marginal Effects of Audience Costs across Dyads}

\begin{tabular}{cc}
\hline & Marginal Effect of $\boldsymbol{\alpha}_{i} \rightarrow-\infty$ \\
\hline$\uparrow \operatorname{Pr}(i$ Backs Down $)$ & $22 \%$ \\
$\uparrow \operatorname{Pr}(j$ Backs Down $)$ & $75 \%$ \\
$\uparrow \operatorname{Pr}(i$ Initiates $)$ & $81 \%$ \\
$\uparrow \operatorname{Pr}(j$ Initiates $)$ & $16 \%$ \\
$\uparrow \operatorname{Pr}($ Peace $)$ & $65 \%$ \\
\hline
\end{tabular}

Note: Percentages denote the proportion of directed dyads where increases in audience costs (toward $-\infty$ ) increase the probability of backing down, the probability of initiating conflict, and the longterm probability of peace. The probabilities, and their associated derivatives, are formally defined in Appendix B in the SI.

Weeks (2008), we consider personalist, single-party, and military autocracies, and from Weeks (2012), we consider machine, junta, boss, and strongman. In both cases, democracies are the excluded category. We uncover the trends she hypothesizes in Table 8 in Appendix G in the SI, where personalist and boss leaders have smaller (closer to $+\infty$ ) audience costs than democracies. Furthermore, machines tend to have more intense audience costs than democracies, but the difference is not significant at conventional levels.

\section{The Effects of Audience Costs}

What are the substantive effects of audience costs on the evolution of interstate conflicts? We consider how changes in audience costs affect countries' propensity to (a) initiate disputes and (b) back down and receive audience costs along the path of play. For each dyad, we compute the marginal effect of making audience costs more negative on each actor's equilibrium probability of backing down and initiating a conflict. We aggregate trends across individual dyads rather than constructing an "average" dyad because there is no information concerning what equilibrium such a dyad would play. Our exercise is theoretical. It describes how the estimated equilibria change as functions of audience costs rather than correlating our audience cost estimates with the observed equilibrium choice probabilities in a reduced-form analysis. As discussed above, the latter approach produces misleading substantive effects, as it ignores the indirect effects of audience costs through countries' equilibrium strategies.

Table 2 reports the percentage of directed dyads where the marginal effect of more intense (negative) audience costs on the indicated probability is positive. First, consider their effects on a country's likelihood of backing down and receiving an audience cost. In $78 \%$ of directed dyads, larger audience costs for country $i$ decrease the frequency $i$ backs down along the equilibrium path of play. This illustrates the hand-tying effect of audience costs, where a country is less likely to concede a dispute as its audience costs increase. Likewise, larger audience costs for country $i$ increase the probability its opponent $j$ backs down along the path of play in $75 \%$ of directed dyads. This is an indirect effect of audience costs through $j$ 's strategy, matching the coercive effects discussed in previous work (Fearon 1994a; Kurizaki and Whang 2015; Partell and Palmer 1999; Uzonyi, Souva, and Golder 2012).

Next, we examine the effects of audience costs on conflict initiation. Counter to intuition, larger audience costs embolden leaders into initiating disputes with greater frequency. In $81 \%$ of directed dyads, as $i$ 's audience costs increase, $i$ is more likely to initiate a dispute along the path of play, despite the possibility that $i$ might pay these larger costs later. This finding runs counter to arguments and empirics in other work, where authors find that larger audience costs temper the propensity for countries to risk conflict (Clark and Nordstrom 2005; Kurizaki and Whang 2015; Prins 2003; Schultz 1998; Weeks 2012). ${ }^{15}$ Nonetheless, it provides the first empirical support for Schultz's (1999) prediction that increased audience costs result in more crisis onsets. In some directed dyads, we find that larger audience costs lead their respective countries to initiate less, but this effect is not prominent, arising in only $19 \%$ of observations.

The emboldening effect arises from credible commitments. Essentially, when country $i$ has larger audience costs, it is more likely to commit to standing firm in the subsequent dispute, as in the hand-tying effect described above. Furthermore, these larger audience costs coerce $i$ 's opponents to back down, as in the coercive effect described above. Countries internalize these advantages when deciding whether to initiate disputes. Because higher audience costs commit their respective countries to stand firm and coerce their rivals to back down, they also encourage countries to initiate disputes, as leaders attempt to exploit their enhanced credibility by becoming more aggressive.

Conversely, in $84 \%$ of dyads, $j$ becomes less likely to initiate disputes as i's audience costs increase. This effect arises for the same credibility concerns described above. When $i$ has larger audience costs, country $j$ knows that its opponent will more easily stand firm during

\footnotetext{
${ }^{15}$ Previous work covering the 1993-2007 time frame uses standard, reduced form regressions. Although Kurizaki and Whang (2015) adopt a structural approach, they use data from 1919-1939.
} 


\section{TABLE 3 Correlates of Audience Costs}

\begin{tabular}{lccc}
\hline & & & $\begin{array}{c}\text { p-value } \\
\text { (one-sided) }\end{array}$ \\
\hline Polity2 & -0.18 & -2.04 & .02 \\
W & -0.13 & -1.49 & .07 \\
Free Press & -0.13 & -1.43 & .08 \\
Elected Executive & -0.20 & -2.29 & .01 \\
Executive Removal & -0.14 & -1.51 & .07 \\
Executive Constraints & -0.09 & -1.04 & .15 \\
Rivalry & 0.32 & 3.78 & .00 \\
USG's ACC & -0.25 & -2.34 & .01 \\
\hline
\end{tabular}

disputes, and, as a result, $j$ is relatively disadvantaged and will be more likely to concede. Thus, $j$ avoids this relative weakness by initiating less; that is, increasing $i$ 's audience costs deters opponent $j$ 's beginning new disputes.

These results motivate a substantive question: Are larger audience costs beneficial for peace? On the one hand, raising a country's audience costs encourages it to initiate conflicts and stand firm in disputes. On the other hand, larger costs also encourage opponents to back down and not initiate new disputes. We calculate the marginal effect of making audience costs more negative on each directed dyad's probability of peace in the long run. ${ }^{16} \mathrm{Sim}$ ple tallying demonstrates that in $65 \%$ of directed dyads, increasing an actor's audience cost results in more peace. Specifically, in $38 \%$ of dyads, increasing either country's audience costs makes both sides more peaceful, whereas both sides becomes more conflictual in only $8 \%$. In the remaining $54 \%$, the effects are mixed. When we sum the marginal effects of increasing both actors' audience costs, we find that in $80 \%$ of undirected dyads, the total effect is an increase in peace. This analysis demonstrates that the dominant effect of audience costs is their deterrence value: Countries tend not to initiate disputes against countries with higher audience costs, leading to more peace in the long run.

\section{The Correlates of Audience Costs}

We explore the best proxies for audience costs by first considering how well standard proxies associate with the estimates in Figure 1. Table 3 reports the relevant correlation coefficients. In particular, we consider a

\footnotetext{
${ }^{16}$ The long-run probability of peace comes from the dyad's invariant (stationary) distribution. We describe this in Appendix B in the SI. In Appendix K, we provide evidence that equilibrium play has converged to its invariant distributions in most dyads.
}

country's polity2 score, Bueno de Mesquita and colleagues' (2005) W, a dummy for free press from Freedom House (Karlekar and Dunham 2012) and supplemented by $\mathrm{Li}$ (2005), whether the executive is directly elected (Regan, Frank, and Clark 2009), whether constitutional provisions exist for executive removal (Regan, Frank, and Clark 2009), a measure of executive constraints from the polity 2 data, the number of interstate rivals the country has (Thompson and Dreyer 2012), ${ }^{17}$ and a past proxy for audience costs from Uzonyi, Souva, and Golder (2012), which they call "audience cost capacity" (ACC).

The simple bivariate relationships suggest that many of the standard proxies do a fair, but unimpressive, job of capturing audience costs. The democracy-based proxies are all significant and correlate in the expected direction. Because Kurizaki and Whang's (2015) audience cost measures are a linear function of polity 2 scores, imputing audience costs using their coefficient estimates with polity2 scores from our data (i.e., mean polity 2 from 1993 to 2007) will produce a correlation coefficient $(0.18)$ identical in magnitude to that of polity 2 in Table 3 . Furthermore, the relationship between a free press and the strength of audience costs matches the theoretical predications in Slantchev (2006). These relationships, however, raise important questions about the appropriateness of using any one variable to stand in for audience costs in empirical work.

To analyze potentially more intricate relationships between these proxies and audience costs, we consider a regression tree. We include all the variables from Table 3, except for executive constraints and ACC, which are removed because they are composed of polity 2 components. Additionally, we add dummies for various types of democratic electoral systems from Regan, Frank, and Clark (2009). The output of the regression tree is shown in Figure 2; values at each terminal node refer to the average audience cost among classified countries and the percentage of observations at the node.

According to this method, the best predictor of large audience costs is whether a country has a polity 2 score greater than or equal to $-4 .{ }^{18}$ Among autocracies, those that do not have any institutions for executive removal are the countries with the lowest audience costs. That is, the truest of autocrats have an average audience cost of

\footnotetext{
${ }^{17}$ Thompson and Dreyer $(2012,11)$ identify interstate rivals by "avoid[ing] the conflict record and focus[ing] on who state decision makers (or their historians) say are or have been their competitive and threatening enemies."

${ }^{18}$ This is similar to Kurizaki and Whang (2015), who find that a -5 polity2 score is an important cutoff. In their case, it is the cutpoint for whether audience costs exist. Here, it is the cutpoint that best predicts high versus low audience costs.
} 


\section{FIGURE 2 Regression-Tree Predictors of Audience Costs}

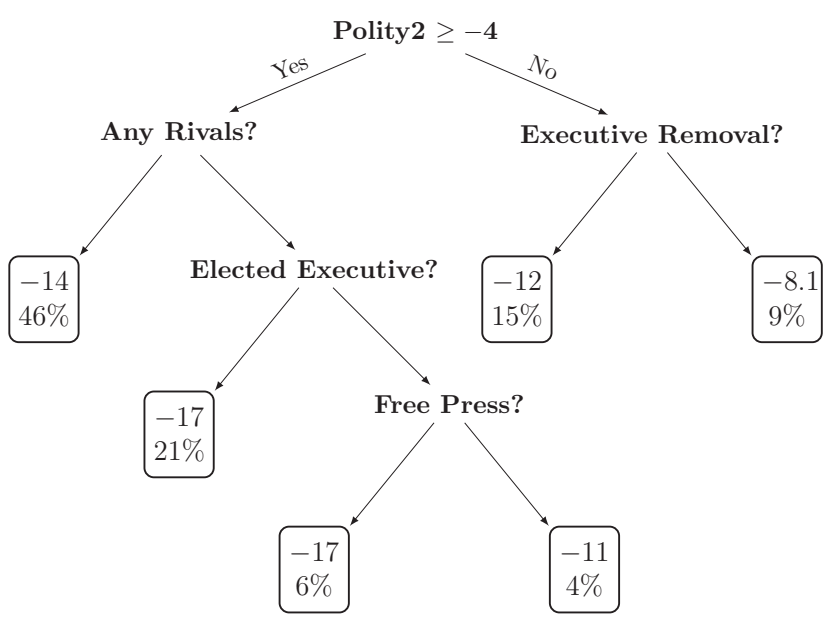

-8 and include Saudi Arabia and Swaziland. In contrast, those with legal provisions for executive removal (e.g., China and Vietnam) have larger costs, with an average of -12 .

Looking at democracies and anocracies (i.e., those with a polity score above -4 ), the next most important predictor-before any other domestic institution-is the existence of an interstate rival. Countries in this group include many powerful states, such as the United States and Russia, as well as minor powers, such as Iran and India. Thus, while democratic institutions are generally associated with larger audience costs, having a rival attenuates their magnitude.

Countries with polity2 scores larger than -4 but without an interstate rival are split based on whether the chief executive is directly elected. In countries where there are direct elections, leaders face large costs, with an average of -17 , which is substantial compared to the other groups in the regression tree. Countries in this category include a grab bag of strong and weak democracies, such as France and Brazil. Notice that in countries without direct elections of the executive, the existence of a free press has the same effect as direct election; that is, a free press can generate relatively large audience costs, again confirming a result from the formal model in Slantchev (2006). Countries at this node are mostly parliamentary democracies.

The final node on the tree considers non-autocratic countries without rivals, a directly elected executive, or a free press. These countries tend to be weak democracies and anocracies, such as Indonesia and Cambodia. Audience costs in these regimes are the lowest on this half of the regression tree, indicating the importance of domestic

\section{Figure 3 Audience Costs and Long-Run Peace: North and South Korea}

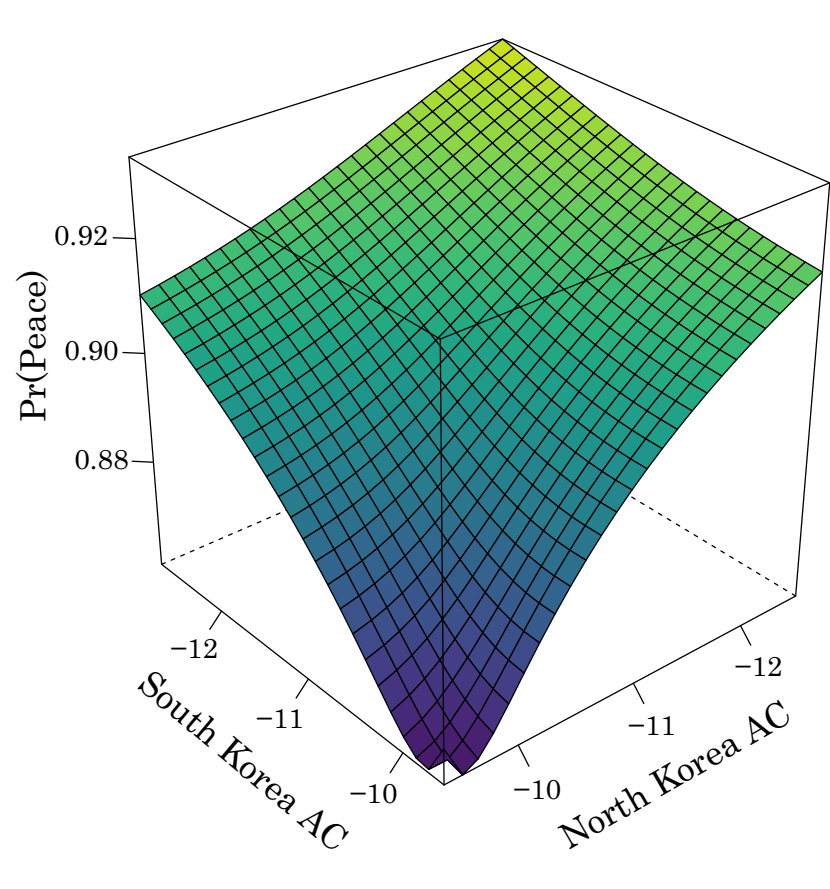

institutions, besides democracy levels, to constrain leaders. When non-autocratic regimes neither directly elect their chief executive nor have a free press, then they have audience costs comparable to those with autocrats. For example, Bangladesh with a polity score of 6 (until 2007) has an audience cost of -1.9 , rivaling the least constrained of autocrats.

\section{Illustrative Examples}

To illustrate these findings, we examine two salient conflicts in greater detail. First, we consider substantive effects from the North and South Korea dyad. Figure 3 graphs the predicted probability of peace along the equilibrium path of play as a function of each player's audience cost. ${ }^{19}$ The graph illustrates the pacifying effects of audience costs. As both costs become more severe (move toward $-\infty$ ), the likelihood of peace in the long run increases. A roughly two-unit change in both cost parameters produces an

\footnotetext{
${ }^{19}$ Multiple equilibria exist in each dyad, which complicates counterfactual experiments. Thus, we cannot just vary the parameters, compute a new equilibrium, and compare choice probabilities under the old and new parameter values. Doing so would not guarantee that the new equilibrium bears any resemblance to the estimated one. To address this problem, we use a method from Aguirregabiria (2012) that maps equilibria as locally continuous functions of data or parameters. Appendix $\mathrm{H}$ in the SI contains more details.
} 


\section{Figure 4 Audience Costs and Long-Run Peace: Israel and Lebanon}

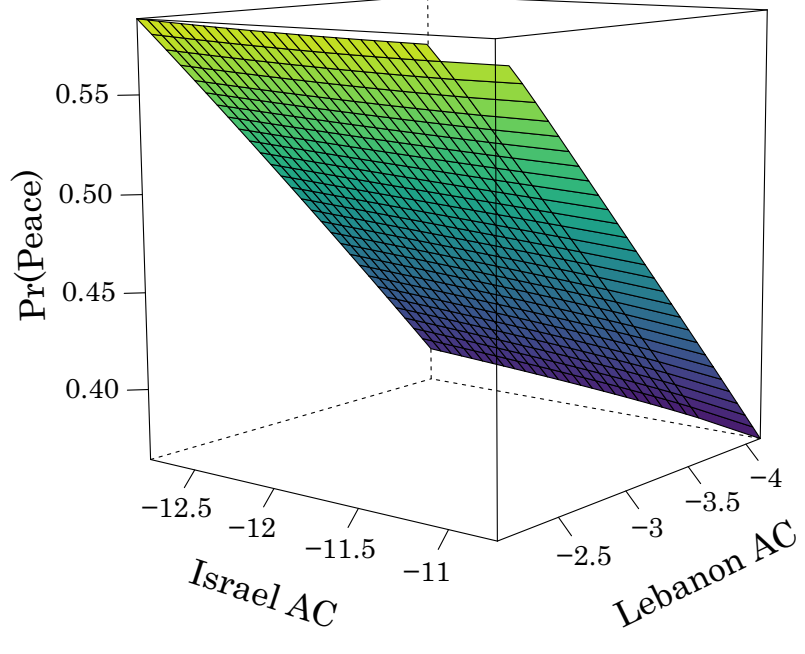

8 percentage point increase in the probability that these countries are at peace.

Some of these trends appear when considering how the relationship between the two countries evolved during the 1990s and 2000s. After Kim Dae-jung assumed the presidency-representing the first peaceful transfer of power to an elected opposition party-South Korea finished its democratic consolidation, and there was an unprecedented push toward peace in the Sunshine Policy (CNN 1998; Lee 2002). In this case, democratic consolidation in South Korea may have increased President Kim's audience costs. ${ }^{20}$ Our analysis suggests that such a shift would make North Korea less likely to initiate a dispute (i.e., the deterrent effect of audience costs). When this interstate rivalry resolidified in the early 2000s, we would have expected South Korea's audience cost to become less intense. Notably, President Bush's "axis of evil" speech is frequently credited with helping return this rivalry to saliency (Lee 2002; Paik 2002). Our analysis suggests that North Korea would become more likely to initiate a dispute as South Korea's audience costs move from -13 to -10 , that is, the range in Figure 3. In contrast, the probability that South Korea would initiate a dispute remains effectively unchanged. Matching this assessment, from the mid-2000s onward there has been a rash of North Korean initiations (Lavelle 2015).

In another case, Figure 4 graphs the effects of audience costs on the conflict between Lebanon and Israel.

\footnotetext{
${ }^{20}$ The substantive effects in Figure 1 could be interpreted as the effects of an unexpected and exogenous change in audience cost parameters on the equilibrium probability of peace. We maintain this interpretation throughout this section.
}

Increasing Israel's audience costs results in more peace, but increasing Lebanon's produces more conflict. To see this, notice that if we were to fix Lebanon's audience cost and only decrease Israel's by one unit, the dyad becomes more hostile, where the probability of peace decreases by approximately 2 percentage points. This prediction has some anecdotal support: Israel's 2006 invasion of Southern Lebanon occurred during a period when (Wolf 2016, 431) argues that the Israeli parliament was particularly fractured and unable to inflict audience costs on the prime minister. During this time, Israeli leadership faced lower audience costs due to poor coordination among opposition parties, and our analysis predicts a lower likelihood of peace, matching the onset of the 2006 conflict.

In contrast, small increases in Lebanon's audience costs generate more conflict, where a unit increase (toward $-\infty$ ) results in a 10 percentage point decrease in the predicted probability of peace. This comparative static is an example where audience costs are positively correlated with conflict in certain directed dyads. Although this effect does not dominate in the data-see Table 2-it appears in $35 \%$ of directed dyads. Upon further inspection, we find that larger audience costs for Lebanon discourage both sides from initiating disputes, but the disputes that do erupt endure for longer periods. Specifically, adjusting Lebanon's audience cost over the range listed in Figure 4 increases conflict duration by 3 to 4 months, on average.

\section{Additional Results}

We note two important findings. First, we find a liberal peace in war but not crisis. ${ }^{21}$ Specifically, the estimates suggest that as joint democracy levels and trade dependence increase, the relative benefit from being in the war state, compared to peace, decreases. However, we find little support that democracies and trading partners avoid entering crises with each other.

Second, we consider the spiraling/deterrence effects of conflict (the $\gamma(s)$ coefficients) from the systemic theories of conflict in Braumoeller (2008). Note that $\gamma$ (PEACE) $<0$, which suggests that in peace, countries are playing something like chicken, and the expectation of conflict deters reciprocation because $i$ receives a strong additional disutility from escalation when it expects $j$ to escalate as well. In contrast, the positive coefficients on $\gamma$ (CRISIS) and (WAR) indicate that once countries are in a dispute, a

${ }^{21}$ Appendix J in the SI contains additional substantive effects, including the effect of joint democracy levels on the probability of peace. 
country's cost of continuing the conflict decreases when its opponent continues as well. In these states, conflict spirals. This indicates that concerns about the security dilemma are particularly relevant when there is an active dispute between two countries.

These substantive finds are robust to several model specifications contained in Appendix I. For example, we control for other variables such as alliances, distance between two countries, and population. Furthermore, we estimate the model with one audience cost parameter, i.e., $\alpha_{i}=\alpha$, and the conclusions remain intact. Finally, Appendix $\mathrm{K}$ contains model fit exercises. We analyze the degree to which the model reproduces the predicted number of states and transitions both in aggregate and within each dyad. Several goodness-of-fit measures indicate good fit, and the structural estimator fits the data better than standard multinomial logits.

\section{Conclusion}

Audience costs are ubiquitous in theories of international relations. We adopt a structural approach to more flexibly estimate audience costs, examine their substantive effects, and test the strength of potential proxies. Contrary to intuition, we find that audience costs embolden their respective countries to initiate disputes. This effect emerges because audience costs serve as a commitment device: Increasing a given country's audience costs encourages it to stand firm during disputes, while coercing its opponents to back down. When deciding whether or not to initiate, countries anticipate these effects, so countries with larger audience costs more freely initiate disputes, capitalizing on their enhanced credibility. Despite this emboldening effect, audience costs are, on the whole, peace enhancing. Audience costs also have a deterrent effect in which countries attempt to avoid beginning disputes against rivals with larger audience costs and the additional leverage the costs entail.

In addition, we find that democracy explains only a portion of the variation in audience costs, and other domestic factors such as executive removal, a directly elected executive, and a free press also contribute to audience costs independently. Our results also highlight an important international determinant: Democracies with rivals tend to have less severe audience costs than democracies without rivals.

Our theoretically and empirically unified approach to analyzing conflict dynamics offers important avenues for future research. First, the model and estimator are flexible enough to incorporate other actors or a more nuanced state space. For the former, the model could be expanded to include international organizations such as the United Nations, and for the latter, we could model the presence of nuclear weapons or diplomatic connections with additional state variables. Second, we provide flexible estimates of audience costs that can be used in future empirical studies as key variables of interest. Third, future work should consider structural models that allow audience costs to be strategically chosen or accumulated over the course of a dispute. Although such an endeavorer entails additional complications, it would better connect more modern theories of audience costs to the structural and empirical enterprise.

\section{References}

Aguirregabiria, Victorll. 2012. “A Method for Implementing Counterfactual Experiments in Models with Multiple Equilibria." Economics Letters 114(2): 190-94.

Aguirregabiria, Victor, and Pedro Mira. 2007. "Sequential Estimation of Dynamic Discrete Games." Econometrica 75(1): $1-53$.

Arcidiacono, Peter, Patrick Bayer, Jason R. Blevins, and Paul B. Ellickson. 2016. "Estimation of Dynamic Discrete Choice Models in Continuous Time with an Application to Retail Competition.” Review of Economic Studies 83(3): 889931.

Barbieri, Katherine, Omar M. G. Keshk, and Brian Pollins. 2009. "Trading Data: Evaluating Our Assumptions and Coding Rules." Conflict Management and Peace Science 26(5): 47191.

Braumoeller, Bear F. 2008. "Systemic Politics and the Origins of Great Power Conflict." American Political Science Review 102(1): 77-93.

Bueno de Mesquita, Bruce, Alastair Smith, Randolph M. Siverson, and James D. Morrow. 2005. The Logic of Political Survival. Cambridge, MA: MIT Press.

Chiozza, Giacomo, and H. E. Goemans. 2011. Leaders and International Conflict. New York: Cambridge University Press.

Clark, David H., and Timothy Nordstrom. 2005. "Democratic Variants and Democratic Variance: How Domestic Constraints Shape Interstate Conflict." Journal of Politics 67(1): 250-70.

CNN. 1998. "Opposition Boycott Shadows South Korea's New President." CNN World News. http://www.cnn.com/ WORLD/9802/24/s.korea.wrap/index.html.

Dafoe, Allan, and Devin Caughey. 2016. "Honor and War: Southern U.S. Presidents and the Effects of Concern for Reputation." World Politcs 68(2). Forthcoming.

Egesdal, Michael, Zhenyu Lai, and Che-Lin Su. 2013. "Estimating Dynamic Discrete-Choice Games of Incomplete Information." Unpublished manuscript.

Fearon, James D. 1994a. "Domestic Political Audiences and the Escalation of International Disputes." American Political Science Review 88(3): 577-92. 
Fearon, James D. 1994b. "Signaling versus the Balance of Power and Interests: An Empirical Test of a Crisis Bargaining Model." Journal of Conflict Resolution 38(2): 236-69.

Feenstra, Robert C., Robert Inklaar, and Marcel P. Timmer. n.d. "The Next Generation of the Penn World Table." available for download at www.ggdc.net/pwt.

Gartzke, Erik. 1998. "Kant We All Just Get Along? Opportunity, Willingness, and the Origins of the Democratic Peace." American Journal of Political Science 42(1): 1-27.

Gleditsch, Kristian S. 2002. "Expanded Trade and GDP Data." Journal of Conflict Resolution 46: 712-24.

Hotz, V. Joseph, and Robert A. Miller. 1993. "Conditional Choice Probabilities and the Estimation of Dynamic Models." Review of Economic Studies 60(3): 497-529.

Huth, Paul K., and Todd L. Allee. 2002. "Domestic Political Accountability and the Escalation and Settlement of International Disputes." Journal of Conflict Resolution 46(6): 75490.

Jo, Jinhee. 2011. "Nonuniqueness of the Equilibrium in Lewis and Schultz's Model." Political Analysis 19(3): 351-62.

Karlekar, Karin Deutsch, and Jennifer Dunham. 2012. "Freedom of the Press 2012." Freedom House. http://www. freedomhouse.org/report-types/freedom-press.

Kenwick, Michael R., Matthew Lane, Benjamin Ostick, and Glenn Palmer. 2013. "Codebook for the Militarized Interstate Incident Data, Version 4.0.” Unpublished manuscript.

Kurizaki, Shuhei. 2007. "Efficient Secrecy: Public versus Private Threats in Crisis Diplomacy." American Political Science Review 101(3): 543-58.

Kurizaki, Shuhei, and Taehee Whang. 2015. "Detecting Audience Costs in International Disputes." International Organization 69(4): 949-80.

Lavelle, Moira. 2015. "A Brief History of Border Conflict between North and South Korea." PRI's The World. http:// www.pri.org/stories/2015-08-20/brief-history-borderconflict-between-north-and-south-korea.

Lee, Manwoo. 2002. "Sunset for Kim Dae-jung's Sunshine Policy?” Current History 101(654): 161-71.

Leventoglu, Bahar, and Ahmer Tarar. 2005. "Prenegotiation Public Commitment in Domestic and International Bargaining." American Political Science Review 99(3): 419-33.

Levy, Jack S. 2012. "Coercive Threats, Audience Costs, and Case Studies." Security Studies 21(3): 383-90.

Levy, Jack S., Michael K. McCoy, Paul Poast, and Geoffrey P. R. Wallace. 2015. "Backing Out or Backing In? Commitment and Consistency in Audience Costs Theory." American Journal of Political Science 59(4): 988-1001.

Lewis, Jeffrey B., and Kenneth A. Schultz. 2003. "Revealing Preferences: Empirical Estimation of a Crisis Bargaining Game with Incomplete Information.” Political Analysis 11(4): 34567.

Li, Quan. 2005. “Does Democracy Promote or Reduce Transnational Terrorist Incidents?" Journal of Conflict Resolution 49(2): 278-97.

Oneal, John R., and Bruce Russett. 1997. "The Classical Liberals Were Right: Democracy, Interdependence, and Conflict, 1950-1985." International Studies Quarterly 41(2): 267-93.
Paik, Haksoon. 2002. "Assessment of the Sunshine Policy.” Asian Perspective 26(3): 13-35.

Pakes, Ariel, Michael Ostrovsky, and Steven Berry. 2007. "Simple Estimators for the Parameters of Discrete Dynamic Games (with entry/exit examples).” RAND Journal of Economics 38(2): 373-99.

Partell, Peter J., and Glenn Palmer. 1999. "Audience Costs and Interstate Crises: An Empirical Assessment of Fearon's Model of Dispute Outcomes." International Studies Quarterly 43(2): 389-405.

Prins, Brandon C. 2003. "Institutional Instability and the Credibility of Audience Costs: Political Participation and Interstate Crisis Bargaining, 1816-1992." Journal of Peace Research 40(1): 67-84.

Regan, Patrick M., Richard W. Frank, and David H. Clark. 2009. "New Datasets on Political Institutions and Elections, 1972-2005." Conflict Management and Peace Science 26(3): 286-304.

Rust, John. 1987. "Optimal Replacement of GMC Bus Engines: An Empirical Model of Harold Zurcher.” Econometrica 55(5): 999-1033.

Schultz, Kenneth A. 1998. "Domestic Opposition and Signaling in International Crises." American Political Science Review 92(4): 829-44.

Schultz, Kenneth A. 1999. "Do Democratic Institutions Constrain or Inform? Contrasting Two Institutional Perspectives on Democracy and War." International Organization 53(2): 233-66.

Schultz, Kenneth A. 2001. "Looking for Audience Costs." Journal of Conflict Resolution 45(1): 32-60.

Schultz, Kenneth A., Jeffrey B. Lewis, and Cesar Zucco. 2012. "Coercive Diplomacy Data Base" [Data File and Codebook].

Signorino, Curtis S. 1999. "Strategic Interaction and the Statistical Analysis of International Conflict." American Political Science Review 93(2): 279-97.

Silvey, S. D. 1959. “The Lagrangian Multiplier Test." Annals of Mathematical Statistics 30(2): 389-407.

Singer, J. David, Stuart A. Bremer, and John Stuckey. 1972. "Capability Distribution, Uncertainty, and Major Power War, 1820-1965." In Peace, War, and Numbers, ed. Bruce Russett. Beverly Hills: Sage Publications.

Slantchev, Branislav L. 2006. "Politicians, the Media, and Domestic Audience Costs." International Studies Quarterly 50(2): 445-77.

Slantchev, Branislav L. 2012. "Audience Cost Theory and Its Audiences." Security Studies 21(3): 376-82.

Smith, Alastair. 1998. "International Crises and Domestic Politics.” American Political Science Review 92(3): 623-38.

Snyder, Jack, and Erica D. Borghard. 2011. "The Cost of Empty Threats: A Penny, Not a Pound." American Political Science Review 105(3): 437-56.

Su, Che-Lin, and Kenneth L. Judd. 2012. "Constrained Optimization Approaches to Estimation of Structural Models." Econometrica 80(5): 2213-30.

Thompson, William R., and David R. Dreyer. 2012. Handbook of International Rivalries: 1494-2010. Los Angeles: CQ Press. 
Tomz, Michael. 2007. "Domestic Audience Costs in International Relations: An Experimental Approach.” International Organization 61(4): 821-40.

Uzonyi, Gary, Mark Souva, and Sona N. Golder. 2012. “Domestic Institutions and Credible Signals." International Studies Quarterly 56(4): 765-76.

Weeks, Jessica L. 2008. "Autocratic Audience Costs: Regime Type and Signaling Resolve." International Organization 62(1): 35-64.

Weeks, Jessica L. 2012. "Strongmen and Straw Men: Authoritarian Regimes and the Initiation of International Conflict." Amercian Political Science Review 106(2): 326-47.

Whang, Taehee, Elena V. McLean, and Douglas W. Kuberski. 2013. "Coercion, Information, and the Success of Sanction Threats." American Journal of Political Science 57(1): $65-81$.

Wolf, Albert B. 2016. "Backing Down and Domestic Political Survival in Israel.” Polity 48(3): 414-39.

\section{Supporting Information}

Additional Supporting Information may be found in the online version of this article at the publisher's website:

Appendix A: Characterizing Equilibria

Appendix B: Example Equilibrium

Appendix C: Implementation

Appendix D: Monte Carlo Experiments

Appendix E: Time-Invariant Covariates

Appendix F: Audience Cost Parameters

Appendix G: Audience Costs in Autocratic Regimes

Appendix H: Substantive Effects

Appendix I: Robustness Checks

Appendix J: Additional Substantive Effects

Appendix K: Model Fit 